\title{
CONTROL AN ACTIVE SUSPENSION SYSTEM BY USING PID AND LQR CONTROLLER
}

\section{NGUYEN TUAN ANH}

Lecturer, Automotive Engineering Department, Thuyloi University, 175 Tay Son, Dong Da, Hanoi, Vietnam

\begin{abstract}
The suspension has a very important effect on the comfort and stability of the vehicle on the move. To improve safety issues as well as comfort and convenience, the active suspension system is used to replace the conventional mechanical suspension system (passive suspension system). There are many controllers used to control the active suspension system such as PID controller, LQG controller, LPV controller. This research focuses on analyzing, evaluating, comparing, and applying two controllers: PID controller and LQR controller for an active suspension system. The results of the research have shown that when the vehicle is equipped with an active suspension system, the values of displacement and acceleration of the sprung mass are significantly improved. Besides, the PID controller supports to optimize the body's acceleration, the LQR controller supports to optimize the body's displacement. This research will be the basis for supporting more complex researches in the future.
\end{abstract}

KEYWORDS: Active Suspension System, PID Controller, LQR Controller, Dynamic Vehicle Model

Received: Jun 06, 2020; Accepted: Jun 26, 2020; Published: Aug 06, 2020; Paper Id.: IJMPERDJUN2020662

\section{INTRODUCTION}

The suspension system of the vehicle is the soft link between the wheel and the body. The suspension system is capable of regulating and quenching vibrations from the road surface. Besides, the suspension system supports the stability of the vehicle in the case of steering or turning around [1-4]. The conventional mechanical suspension system (passive suspension system) can't meet the problems of the comfort and stability of the vehicle when moving. Therefore, the active suspension system has been used to replace the passive suspension system. The active suspension system is equipped with a hydraulic cactuator between the sprung mass and the un-sprung mass. This system is automatically controlled via ECU and sensors $[5,6]$. When the vehicle goes through a bumpy road, the sensor will record information about the acceleration of the vehicle's body. This information is then sent to the ECU controller. Here, the ECU will analyze, evaluate, and send the current signal $i(t)$ to the actuator. The actuator (hydraulic piston-cylinder assembly) will produce FA thrust acting on the sprung mass and the un-sprung mass. Therefore, the comfort of the vehicle can be improved. However, due to the complicated control process and the high price, the active suspension system is only used on high-class models.

In recent years, there have been many studies on optimizing the comfort of the suspension system [7-10]. Besides, articles regarding the control active suspension system have also been published. In these studies, the most commonly used control methods are PID, LQG, LPV, Fuzzy Logic,... [11-35]. In general, the results of the above articles show the advantages of the active suspension system compared to the conventional passive suspension system. Each control method will have its advantages and disadvantages, corresponding to the vehicle's moving conditions. 
This research focuses on modeling the active suspension control process using the PID controller and the LQR controller. The parameters of these two controllers were calculated and optimized to achieve the highest results.

\section{CONTROL MODEL}

\section{Dynamic Vehicle Model}

As usual, the dynamic quarter vehicle model of the vehicle is used in the studies of control and optimization of the comfort of the suspension system.

The dynamic quarter vehicle model of the vehicle is given as shown in Figure 1

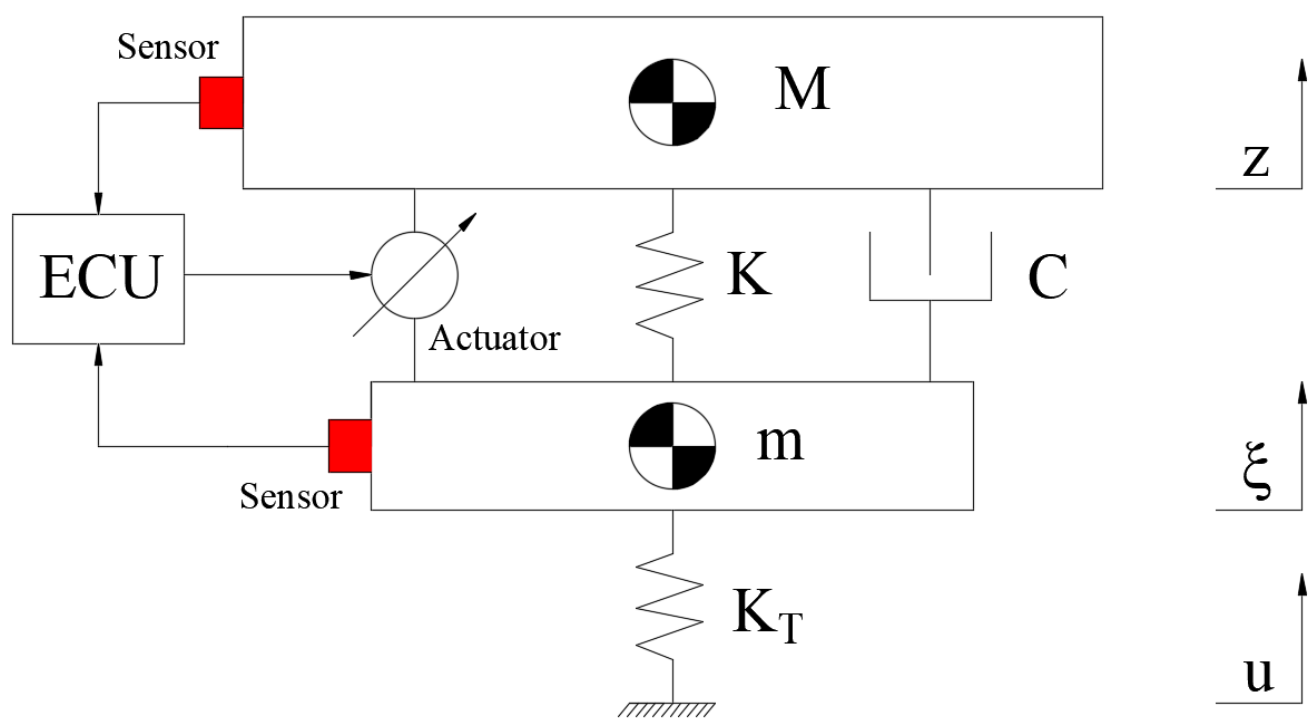

Figure 1: Dynamic Quarter Vehicle Model.

The equations describing the oscillation of the vehicle are shown as follows:

$$
\begin{aligned}
& M \ddot{z}=F_{K}+F_{C}+F_{A} \\
& m \ddot{\xi}=F_{K T}-F_{K}-F_{C}-F_{A}
\end{aligned}
$$

Where

$$
\begin{aligned}
& F_{K}=K(\xi-z) \\
& F_{C}=C(\dot{\xi}-\dot{z}) \\
& F_{K T}=K_{T}(u-\xi)
\end{aligned}
$$

\section{PID Controller}

PID controllers are commonly used in the field of industrial control. This controller has the advantage of being simple, compact, durable, and low cost. However, the PID controller can only receive a single-input. Therefore, complex models can't use the PID controller. 
The diagram of the PID controller is shown in Figure 2. The signal e(t) after going into the PID controller will be processed by 3 algorithms:

+ Proportion algorithm: $K_{p} e(t)$

+ Integrationalgorithm: $K_{i} \int_{0}^{t} e(\tau) d \tau$

+ Derivationalgorithm: $K_{d} \frac{d e(t)}{d t}$

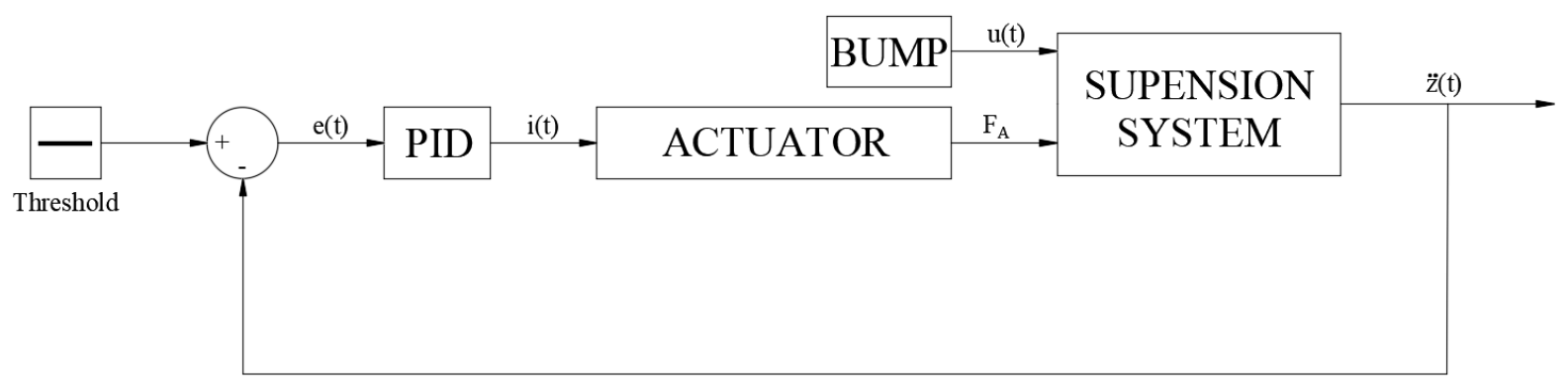

Figure 2: PID Controller Schematic.

\section{LQR Controller}

The LQR controller (Linear Quadratic Regulator) is the optimal controller. This controller can use the multi-input parameters of the pre defined model. To obtain the output signal $\mathrm{i}(\mathrm{t})$, the coefficient $\mathrm{R}$ needs to be calculated.

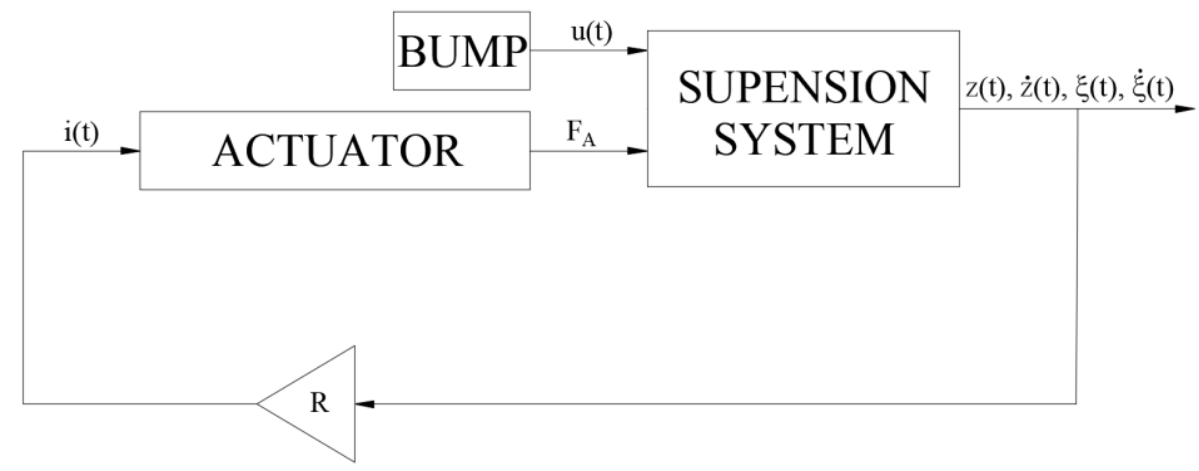

Figure 3: LQR Controller Schematic.

Let's $\mathrm{Q}$ is the cost function:

$Q=\frac{1}{2} \int_{0}^{\infty} x^{T}\left(C+R^{T} D R\right) x d t=\frac{1}{2} \int_{0}^{\infty} x^{T} K x d t$

Through (2.6) can easily identify R.

The equations established in section 2.1 can transform into the following matrix form: 


$$
\left\{\begin{array}{l}
\dot{x}(t)=A x(t)+B u(t) \\
y(t)=C x(t)+D u(t)
\end{array}\right.
$$

The matrix $\mathrm{A}$ is a state matrix, matrix $\mathrm{B}$ is an input matrix, matrix $\mathrm{C}$ is an output matrix, and matrix $\mathrm{D}$ is a navigation matrix.

$$
\begin{aligned}
A & =\left[\begin{array}{cccc}
0 & 0 & 1 & 0 \\
0 & 0 & 0 & 1 \\
-\frac{K}{M} & \frac{K}{M} & -\frac{C}{M} & \frac{C}{M} \\
\frac{K}{m} & -\frac{\left(K+K_{T}\right)}{m} & \frac{C}{m} & -\frac{C}{m}
\end{array}\right] \quad B=\left[\begin{array}{c}
0 \\
0 \\
0 \\
\frac{K_{T}}{m}
\end{array}\right] \\
C & =\left[\begin{array}{cccc}
c_{11} & 0 & 0 & 0 \\
0 & c_{22} & 0 & 0 \\
0 & 0 & c_{33} & 0 \\
0 & 0 & 0 & c_{44}
\end{array}\right] \quad D=\left[d_{11}\right]
\end{aligned}
$$

\section{RESULTS}

The research used reference parameters as shown in Table 3.1.

Table 1:Vehicle Specifications

\begin{tabular}{|c|l|c|c|}
\hline Symbol & \multicolumn{1}{|c|}{ Description } & Value & Unit \\
\hline $\mathrm{M}$ & Sprung mass & 350 & $\mathrm{~kg}$ \\
\hline $\mathrm{m}$ & Un-sprung mass & 50 & $\mathrm{~kg}$ \\
\hline $\mathrm{C}$ & Damping coefficient & 3000 & $\mathrm{Ns} / \mathrm{m}$ \\
\hline $\mathrm{K}$ & Stiffness of the srping & 35000 & $\mathrm{~N} / \mathrm{m}$ \\
\hline $\mathrm{K}_{\mathrm{T}}$ & Stiffness of the tire & 100000 & $\mathrm{~N} / \mathrm{m}$ \\
\hline
\end{tabular}

The excitation signal from the road surface $\mathrm{u}(\mathrm{t})$ is shown in the following two cases:

+ Case 1: $u(t)=\left\{\begin{array}{l}0, t<0 \\ 0.05,1 \leq t \leq 2 \\ 0, t>2\end{array}\right.$

+ Case 2: $u(t)=\left\{\begin{array}{l}0, t<1 \\ 0.05, t \geq 1\end{array}\right.$

For each case, the values of displacement and acceleration of the vehicle's body will be compared.

\section{Case 1}

The displacement of sprung mass is described as shown in Figure 4. If the vehicle only uses a passive suspension system, the value of the displacement of the sprung mass will be very large, $\mathrm{z}_{\max }=78.5(\mathrm{~mm})$. If the vehicle is equipped with an 
active suspension system, this value can be significantly reduced. The maximum value of the displacement $Z_{m a x}$ corresponding to the LQR controller and the PID controller is $44.9(\mathrm{~mm})$ and $60.1(\mathrm{~mm})$, respectively.

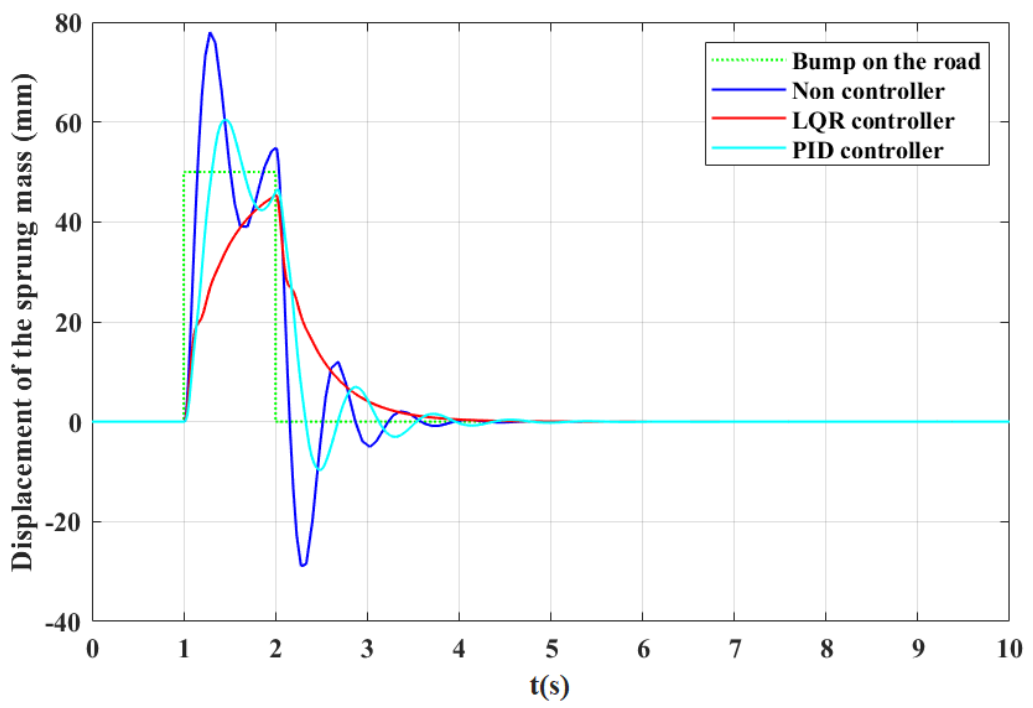

Figure 4: Displacement of the Sprung Mass.

The acceleration of the sprung mass also varies greatly when the vehicleis equipped with an active suspension system. These values are maximized at $9.1\left(\mathrm{~m} / \mathrm{s}^{2}\right), 5.7\left(\mathrm{~m} / \mathrm{s}^{2}\right)$ and $4.0\left(\mathrm{~m} / \mathrm{s}^{2}\right)$, respectively, in the case non controller, LQR controller, and PID controller.

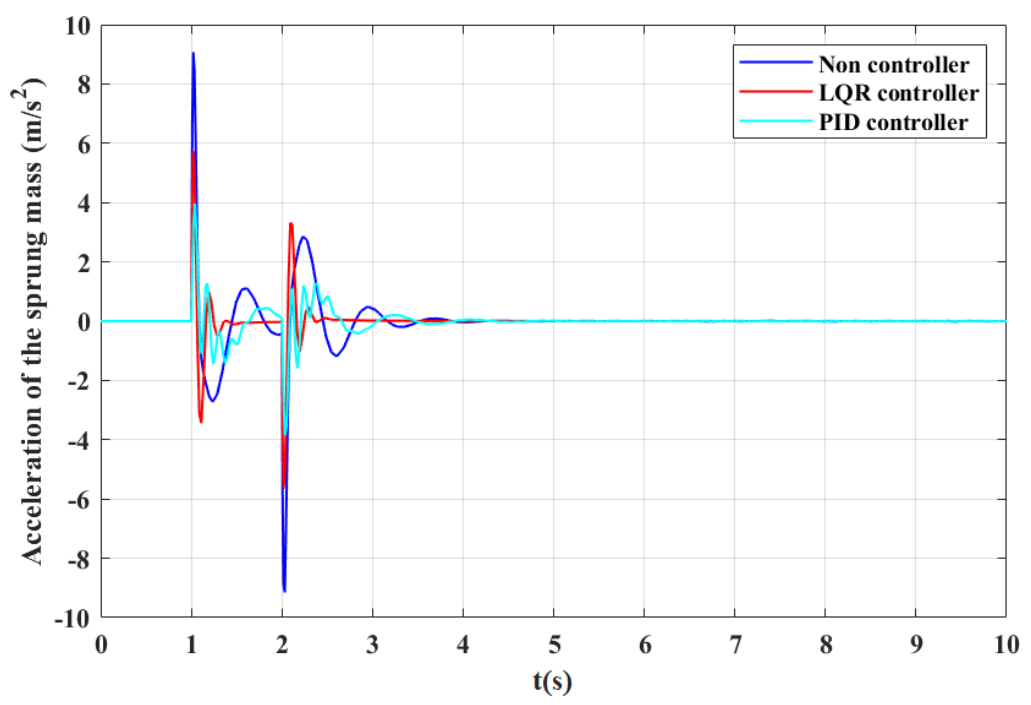

Figure 5: Acceleration of the Sprung Mass.

\section{Case 2}

Figure 6 describes the displacement of the sprung mass in case 2. In general, if the vehicle is n't equipped with an active suspension system, the value of $z_{\max }$ will be very large and fluctuate continuously for approximately 3(s). If the vehicle uses an active suspension system with the PID controller, the amplitude of oscillation willbemuchsmaller. However, if replacing the PID controller with the LQR controller, the amplitude and frequency of oscillation are almost clearly optimized. 


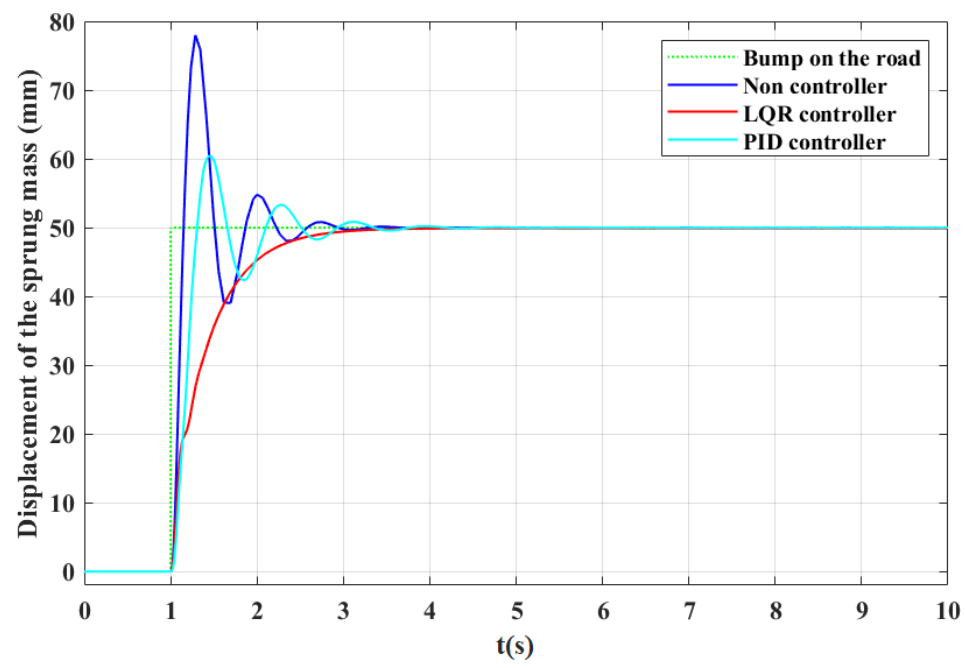

Figure 6: Displacement of the Sprung Mass.

The acceleration of the sprung mass also varies greatly when the vehicle is equipped with the active suspension system (Figure 7). The acceleration of the sprung mass when using the PID controller has a smaller amplitude than that of the LQR controller. However, its oscillation frequency is larger.

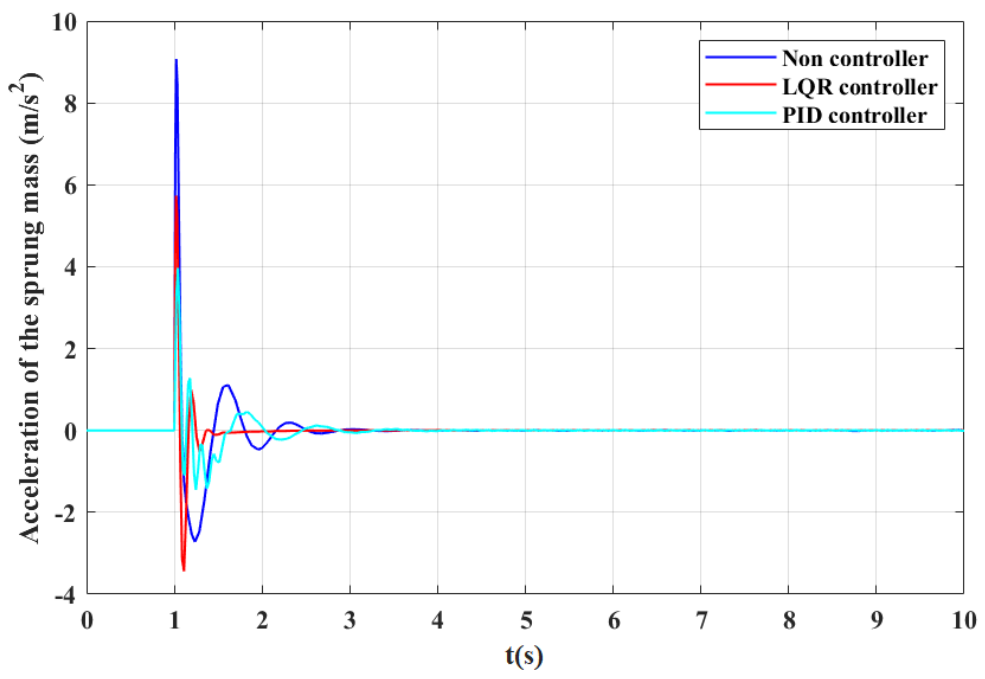

Figure 7: Acceleration of the Sprung Mass.

\section{CONCLUSIONS}

The suspension ensures the comfort and stability of the vehicle when moving on the road. However, the conventional mechanical suspension system (passive suspension system) can't solve the problem sposed to vehicles. Therefore, the active suspension system is used instead.

The active suspension system is controlled automatically, quickly, and accurately. The main methods used to control this suspension are PID, LQR, LQG, LPV, FuzzyLogic, ...

This research focused on the analysis, evaluation, and application of two the active suspension system controllers: PID Controller and LQR Controller. Overall, when the vehicle is equipped with an active suspension system, the comfort and stability of the vehicle can be significantly improved. The PID controller supports to optimize the acceleration of the 
sprung mass. On the other hand, the LQR controller supports to optimize the displacement of the sprung mass. Therefore, the limit of the oscillation needs to be pre defined to select the appropriate controller.

\section{REFERENCES}

1. Konieczny L., Burdzik R. (2017). Modern Suspension Systems for Automotive Vehicles and their Test Methods. Vibro engineering Journal, 14, 233-237. DOI: 10.21595/vp.2017.19238

2. Narayan S., Alsagri A., Gupta V. (2019). The Design and Analysis of Hybrid Automotive Suspension System. International Journal of Mechanical and Production Engineering Research and Development, 9(4), 637-642. DOI: 10.24247/ijmperdaug201963

3. Vijayakrishna, K., and P. R. Sagar. "Robust Controller for Aircraft Yaw." International Journal of Electrical and Electronics Engineering Research 4.2 (2014): 65-70.

4. Agharkakli A., Sabet G. S., Barouz A. (2012). Simulation and Analysis of Passive and Active Suspension System Using Quarter Car Model for Different Road Profile. International Journal of Engineering Trends and Technology, 3(5), 636-644.

5. Shirahatti A. M. (2015). Analysis and Simulation of Active Suspension System for Full Vehicle Model Subjected to Random Road Profile. International Journal of Innovative Research in Science, Engineering and Technology, 4(1), 18489-18502. DOI:10.15680/IJIRSET.2015.0401012

6. Gnanaraj, F. Fredrick, and $K R$ Vijaya Kumar. "Analysis of Vibration Detection using Active Controller in the Smart Cantilever Composite Beam with $L Q R$ and Fuzzy Techniques."International Journal of Mechanical and Production Engineering Research and Development (IJMPERD) 8. 5, Oct 2018, 67-76

7. Bai R., Guo D. (2018). Sliding-mode Control of the Active Suspension System with the Dynamics of a Hydraulic Actuator. Complexity, (12), 1-6. DOI: 10.1155/2018/5907208

8. Riduan A. F. M., Tamaldin N., Sudrajat A., Ahmad F. (2018). Review on Active Suspension System. SHS Web of Conferences, 49, 1-8. DOI: 10.1051/shsconf/20184902008

9. Maurya V. K., Bhangal N. S. (2018). Optimal Control of Vehicle Active Suspension System. Journal of Automation and Control Engineering, 6(1), 22-26. DOI: 10.18178/joace.6.1.22-26

10. Hegde, Sharat S., Sagar Chakole, and Vatsal Vora. "Development of Self Balancing Robot With PID Control." International Journal of Robotics Research and Development (IJRRD) 7.1 (2017): 1-6.

11. Nguyen T. A. (2006). Application of Optimization Methods to Controller Design for Active Suspensions. Master Thesis, Brandenburg University of Technology, Cottbus.

12. Jamil M., Janjua A. A., Rafique I., Butt S. I., Ayaz Y., Gilani S. O. (2013). Optimal Control Based Intelligent Controller for Active Suspension System. Life Science Journal, 10(12), 653-659.

13. Soh M., Jang H., Park J., Sohn Y., Park K. (2018). Development of Preview Active Suspension Control System and Performance Limit Analysis by Trajectory Optimization. International Journal of Automotive Technology, 19(6), 1001-1012. DOI: 10.1007/s12239-018-0097-x

14. Hussein, Dhurgham Salah, and Muhannad Al-Waily. "Active vibration control analysis of pipes conveying fluidrested on different supports using state-space method." International Journal of Energy and Environment 10.6 (2019): 329-344.

15. Rizvi S. M. H., Abid M., Khan A. Q., Satti S. G., Latif J. (2018). Hoo Control of 8 Degrees of Freedom Vehicle Active Suspension System. Journal of King Saud University-Engineering Science, 30, 161-169. DOI: 10.1016/j.jksues.2016.02.004 
16. Youness S. F., Lobusov E. C. (2019). Networked Control for Active Suspension System. Proceedings of the 13th International Symposium Intelligent Systems, Moscow, 123-130. DOI: 10.1016/j.procs.2019.02.025

17. Nagarkar M. P., Vikhe G. J., Borole K. R., Nandedkar V. M. (2011). Active Control of Quarter-Car Suspension System Using Linear Quadratic Regulator. International Journal of Automotive and Mechanical Engineering, 3, 364-372. DOI: 10.15282/ijame.3.2011.11.0030

18. Kaleemullah M., Faris W., Ghazaly N. M. (2019). Analysis of Active Suspension Control Policies for Vehicle Using Robust Controllers. International Journal of Advanced Science and Technology, 28(16), 836-855.

19. Kumar M. S., Vijayarangan S. (2007). Analytical and Experimental Studies on Active Suspension System of Light Passenger Vehicle to Improve Ride Comfort. Mechanika, 65(3), 34-41.

20. Gong M., Wang H., Wang X. (2019). Active Suspension Control Based on Estimated Road Class for Off-Road Vehicle. Mathematical Problems in Engineering, 2019, 1-17. DOI: 10.1155/2019/3483710

21. Fu Z. J., Li B., Ning X. B., Xie W. D. (2017). Online Adaptive Optimal Control of Vehicle Active Suspension Systems Using Single-Network Approximate Dynamic Programming. Mathematical Problems in Engineering, 2017, 1-9. DOI: $10.1155 / 2017 / 4575926$

22. Pang H., Chen Y., Chen J., Liu X. (2017). Design of LQR Controller for Active Suspension without Considering Road Input Signals. Shock and Vibration, 2017, 1-13. DOI: 10.1155/2017/6573567

23. Haemers M., Derammelaere S., Ionescu C. M., Stockman K., Viaene J. D., Verbelen F. (2018). Proportional-Integral StateFeedback Controller Optimization for a Full-Car Active Suspension Setup using a Genetic Algorithm. Proceedings of the IFAC Conference on Advances in Proportional-Integral-Derivative Control, Ghent, Belgium, 1-6. DOI: 10.1016/j.ifacol.2018.06.004

24. Meng Q., Chen C. C., Wang P., Sun Z. Y., Li B. (2019). Study on Vehicle Active Suspension Control Method Based on Homogeneous Domination Approach. Asian Journal of Control, 2019, 1-11. DOI: 10.1002/asjc.2242

25. Bello M. M., Shafie A. A., Khan R. (2015). Active Vehicle Suspension Control using Full State-feedback Controller. Advanced Materials Research, 1115, 440-445. DOI: 10.4028/www.scientific.net/AMR.1115.440

26. Alexandru C., Alexandru P. (2011). Control Strategy for an Active Suspension System. International Journal of Mechanical, Aerospace, Industrial, Mechatronic and Manufacturing Engineering, 5(7), 1204-1209.

27. Koch G. P. A. (2011). Adaptive Control of MechatronicVehicle Suspension Systems. Master Thesis, Technical University Munchen, Munchen.

28. Palanisamy S., Karuppan S. (2016). Fuzzy Control of Active Suspension System. Journal of Vibro engineering, 18(5), $3197-$ 3024. DOI: 10.21595/jve.2016.16699

29. Soleymani M., Montazeri-Gh M., Amiryan R. (2012). Adaptive Fuzzy Controller for Vehicle Active Suspension System Based on Traffic Conditions. Scientia Iranica B, 19(3), 443-453. DOI: 10.1016/j.scient.2012.03.002

30. Turkkan M., Yagiz N. (2013). Fuzzy Logic Control for Active Bus Suspension System. Journal of Physics, 410, 1-4. DOI: 10.1088/1742-6596/410/1/012006

31. Na J., Huang Y., Wu X., Su S. F., Li G. (2020). Adaptive Finite-Time Fuzzy Control of Nonlinear Active Suspension Systems with Input Delay. IEEE Transactions on Cybernetics, 50(6), 2639-2650. DOI: 10.1109/TCYB.2019.2894724

32. Marcu S., Popa D., Stanescu N. D., Pandrea N. (2017). Model for the Study of Active Suspensions. Proceedings of the IOP Conference Series: Materials Science and Engineering, 252, 1-8. DOI: 10.1088/1757-899X/252/1/012032 
33. Guclu R. (2004). Active Suspension Control of Eight Degrees of Freedom Vehicle Model. Mathematical \& Computational Applications, 9(1), 1-10.

34. Zhou Q. (2013). Research and Simulation on New Active Suspension Control System. Master Thesis, Lehigh University, Bethlehem.

35. Susatio Y., Oktaviana L., Rizki N. K., Listijorini E., Biyanto T. R. (2017). Design of Half-car Active Suspension System for Passenger Riding Comfort. IOP Conference Series: Journal of Physics, 1075, 1-7. DOI: 10.1088/1742-6596/1075/1/012030

36. Nguyen T. H., Vu V. T., Dao M. H., Gaspar P., Andras M., Ha T. B. (2017). Using the LQR Control Method on the Active Suspension System of Automobiles, Proceedings of the Vietnam National Mechanics, Hanoi, 1-8.

37. Williams D. E., Haddad W. M. (1997). Active Suspension Control to Improve Vehicle Ride and Handling. Vehicle System Dynamics, 28, 1-24. DOI: 10.1080/00423119708969346

38. Sun Y., Zhao L., Xiang W. (2013). A FuzzyLogic Controller for Vehicle-active Suspension Systems. Advanced Materials Research, 805, 1645-1649. DOI: 10.4028/www.scientific.net/AMR.805-806.1645

39. Zhao Z., Xu L., Liu B., Abdelkareem M. A. A., Zou J., Yu J. (2018). Research on Performance of a Displacement Controllable Active Suspension. Proceedings of the ASME 2018 International Design Engineering Technical Conferences and Computers and Information in Engineering Conference, Quebec, 1-9. DOI: 10.1115/DETC2018-85571 

